\title{
Experiência e descarte: dores humanas e não humanas em um laboratório de neurotoxidade e psicofarmacologia
}

\author{
Guilherme José da Silva e Sá \\ Doutor em Antropologia Social (Universidade Federal do Rio de Janeiro) \\ Professor da Universidade de Brasília \\ guilherme_jose_sa@yahoo.com.br \\ Marcio Felipe Salles Medeiros \\ Mestrando (Universidade Federal de Santa Maria) \\ medeiros.mfs@gmail.com \\ Jonas Silva Schirmann \\ Bacharel em Ciências Sociais (Universidade Federal de Santa Maria) \\ jonasschirmann@yahoo.com.br
}

\begin{abstract}
Resumo Este trabalho é fundamentado em incursões etnográficas realizadas num laboratório de neurotoxidade e psicofarmacologia de em uma universidade brasileira. A partir de uma descrição aprofundada sobre o espaço e as práticas dos agentes que ali atuam, procuramos dar maior ênfase a algumas questões observadas, como as relativas às formas de classificação e categorização do evento-conceito dor construído e inscrito no ambiente de laboratório. Problematizamos também a utilização de modelos animais não humanos (ratos e camundongos) como cobaias em experimentações projetivas. Por fim, tratamos do mapeamento das redes sociotécnicas em que estes atores e procedimentos encontram-se inseridos.
\end{abstract}

Palavras-chave: Etnografia de laboratório; dor; animais; medicamentos; antropologia da ciência.

\section{Introdução}

C ste trabalho está fundamentado na análise dos dados colede neurotoxidade e psicofarmacologia de uma universidade brasileira. Primeiramente, descreveremos o espaço e as práticas dos agentes envolvidos no laboratório, que se propõem a estudar as alterações morfológicas, neuroquímicas e comportamentais induzidas por diversos compostos orgânicos em modelos animais, bem como o efeito de novos fármacos sobre parâmetros comportamentais variados, associados à formação de recursos humanos para pesquisa em todos os níveis. Há duas linhas principais de pesquisa, uma referente ao estudo da memória e a outra ao estudo da dor, e ambas exploram a tentativa de criação de novos fármacos e também de novos métodos de utilização de medi- 
camentos já conhecidos. Neste artigo nos deteremos apenas às pesquisas desenvolvidas pelo laboratório de estudos da dor. ${ }^{1}$

\section{Descrevendo um laboratório}

O núcleo de pesquisas situado em uma universidade pública brasileira constitui-se fisicamente de quatro salas pequenas, pintadas de cinza e branco e repletas de materiais como ração para alimentar as cobaias, inúmeros potes de vidro, aparelhos eletrônicos e livros. A impressão inicial de quem adentra uma dessas salas é a de completa desorganização. Entretanto, com o olhar já mais treinado, é possível perceber uma lógica implícita, pois todos sabem onde se encontram os materiais e onde devem recolocá-los, o que dá indícios de um "caos ordenado".

Na sala que chamaremos de laboratório principal são feitas as pesquisas com as cobaias (ratos e camundongos), três jovens pesquisadores, provenientes do curso de Educação Física, limpavam os locais onde os ratos se encontravam (dois tanques de água, sendo cada um com capacidade para quinhentos litros, contendo resistências no fundo para o aquecimento da água desses reservatórios). Apesar de ser a maior das salas utilizadas, não se pode dizer que seja verdadeiramente espaçosa, cerca de vinte a trinta metros quadrados. Munida de um potente aparelho condicionador de ar para manter constante a temperatura e a umidade do ar e favorecer o manuseio das cobaias, a sala possui ainda uma bancada feita de tijolos claros anexada a vários canos por onde passam água e vários gases. Sobre a bancada dispõem-se vários equipamentos e vidros que cumprem o papel de nos lembrar dos estereótipos associados a um típico laboratório.

Ao serem questionados sobre as atividades ali desenvolvidas, a resposta dos pesquisadores veio em tom baixo dizendo que eram feitos experimentos variados com os animais: desde tentativas de cura para infecções provocadas em laboratório até estudos sobre fadiga muscular, para os quais se utilizavam os tanques de água. Enquanto alguns vidros eram limpados com detergente e hipoclorito, ficamos observando e conversando até voltar novamente ao diálogo acerca dos experimentos, desta vez com um dos pesquisadores-chefes. Sua resposta serviu de alerta para nós: disse que em função das experimentações feitas naquele local seria preciso manter silêncio, pois do contrário os animais poderiam ser afetados. Através daquela repreensão, deixava claro que a influência do ambiente externo poderia ser diretamente sentida na obtenção dos resultados dos experimentos e que a postura dos pesquisadores era fundamental para a manutenção da ordem ou desordem naquele mundo. ${ }^{2}$

Existem diversos projetos em andamento no laboratório, envolvendo distintas áreas de conhecimento como a educação física, a medicina, a química, a engenharia química, a farmácia e a nutrição. É perceptível, ainda que dificilmente atestável, a existência de possíveis relações hierárquicas que mediam esses diferentes pesquisadores. Um exemplo dessa interdependência multidisciplinar vital é o fornecimento de cobaias para o laboratório, realizado por criadouros da própria universidade sob a responsabilidade de outro departamento, o de Zootecnia.

Em uma divisória feita de aglomerado de madeira, uma grande quantidade de fórmulas escritas à caneta para retroprojetor exibe cadeias carbônicas. Resistente ao tempo e às readaptações, as fórmulas e o carbono preservavam suas ligações que precediam a montagem da parede divisória naquele local. Essa reciclagem gerava imagens interessantes como algumas fórmulas em pedaços e outras situadas em pontos íngremes próximas ao vidro que alcança o teto, ou mesmo como uma fórmula disposta de ponta-cabeça.

No fundo da sala há ainda uma espécie de depósito de ração para as cobaias. Uma grande quantidade de sacos cheios desses alimentos é armazenada próximo ao local onde, eventualmente, cobaias utilizadas em algum experimento ficam dispostas. ${ }^{3}$

A segunda sala, chamada "sala da capela", é bem menor e possui, além dos vidros característicos, balanças de precisão, livros, equipamentos e duas capelas, que são utilizadas ao manipular soluções que podem causar risco à saúde de quem ali trabalha. Elas são exaustores que captam vapores tóxicos. Nessa sala

1. Apesar de reconhecermos a existência de extensa bibliografia sobre etnografias feitas em ambientes de laboratório no âmbito da Antropologia da Ciência desde os anos 1970 e de seu caráter relativamente insipiente no Brasil, não nos deteremos aqui à demonstração deste material, uma vez que esta discussão nos parece mais produtiva se abordada diretamente a partir dos problemas do campo empírico. Para um bom levantamento do campo da Antropologia da Ciência no Brasil, ver Sautchuk (2010).

2. Para uma descrição dos procedimentos de "ordenação do mundo" na prática de primatólogos, ver Sá (2006).

3. A combinação entre fórmulas recicladas aleatoriamente dispostas e sacos de ração animal depositados no fundo da sala expõem um aspecto contrastante da composição de um laboratório. Esse "refugo" vital parece conviver pacificamente com a ordem imaculada das bancadas. Esses "espaços antípodas" coexistem também nas exposições de grandes museus de história natural como atestou Aranha Filho (2008). O autor identifica esses "espaços outros" no contexto da renovação das exposições do Museu Nacional no Rio de Janeiro em meados do século XX como um "pandemônio", termo utilizado pelos próprios funcionários envolvidos no processo. Mesmo que, em nosso caso, não tratemos da composição de acervos simetricamente invertidos àquilo que se destacaria em uma coleção, é possível expandir a ideia do "pandemônio" aos ambientes experimentais de laboratório no estilo: "alimento para as bestas" e "fórmulas decaídas". 
são executados vários procedimentos para sintetizar substâncias e muito pouco se trabalha com as cobaias por ali.

A sala ao lado, onde ficam os professores, contém computadores e muitos livros, além de quadros brancos onde os pesquisadores colocam vários avisos. É lá que se faz uso dos computadores para sistematizar pesquisas e atividades.

A última sala, que aqui - para efeito de distinção - denominaremos "sala da memória", situa-se junto ao corredor de entrada e é caracterizada por possuir sua temperatura, umidade e luz controladas. As janelas não possuem persianas, mas sim vidros pintados de branco que bloqueiam a entrada de luz externa, restringindo-se ao uso da iluminação elétrica interna. Ao entrar nessa sala, a sensação que se tem é de estar em um corredor, pois ela possui uma divisória, que fragmenta a sala em três ambientes menores onde são feitos testes com as cobaias. Cada saleta possui uma porta para evitar a desconcentração do animal durante os testes, e, segundo nos foi dito, nesse ambiente o controle de sons e ruídos é também mais rígido que nas demais dependências.

\section{Tipos e modelos de dor}

Durante as experimentações são utilizados dois tipos de cobaias - ratos e camundongos - que são submetidos a diversas práticas que se justificam coadunadas a um sistema classificatório de tipos e modelos de dor. Os tipos de dor, segundo um de nossos interlocutores, baseados em bibliografia especializada sobre o tema (Boyce-Rustay, Honore \& Jarvis, 2010), são: espontânea (dor demonstrada sem a necessidade de uma estimulação auxiliar ou secundária); alodínia (quando um estímulo que normalmente é inócuo passa a ser sentido como nocivo, tal qual um toque simples em uma parte do corpo não dói, mas, se nessa parte houver um corte, fatalmente irá doer); hiperalgesia (sensibilidade aumentada à estimulação nociva, como, por exemplo, colocar uma parte do corpo em água quente dói, queima; se essa parte do corpo estiver cortada, doerá mais ainda).

Esses três tipos estão associados a diversos modelos de dor produzidos a partir de determinadas substâncias e técnicas usadas para causá-los. Os modelos estão intimamente relacionados a essa ligação, pois o objetivo do estudo é justamente verificar se, em situação específica, a dor atenua-se efetivamente ou não.

Pressupõe-se que a dor nos seres humanos não é sentida da mesma forma como nos outros animais, pois, segundo o discurso local, nos primeiros leva-se em consideração sua própria "vivência" (termo entendido como o histórico experiencial de vida de cada indivíduo) e o estímulo para analisar essa dor. Isto determina que cada indivíduo vivencie a dor de uma forma diferente. Essa lógica de pensamento pode ser associada a um tipo de pensamento sistêmico onde o estímulo é a dor e a vivência, a estrutura é o corpo humano, e a reação é a representação da dor que fornece o feedback para saber o que se deve utilizar como paliativo. Sucessivamente depois de aplicada a droga (um novo estímulo), deve-se verificar a nova reação.

Por princípio é essa relação de causa e efeito que se busca dentro do laboratório através das experimentações com as cobaias. Desconsiderando a "vivência" (atributo humano) e tudo aquilo que remeta os aspectos culturais no momento em que é sentida a dor, espera-se que reste apenas o que pode ser "apreendido pela razão" do cientista.

São categorizados também nesse laboratório modelos de dor derivados e relacionados com os tipos de dor já apresentados. Dentre eles podemos citar:

Capsaicina: princípio pungente da pimenta vermelha. Ativa receptores específicos (TRPV1) que provocam dor em queimação. Pode ser injetado na pata (dor/estímulo periférica) para avaliar o tempo que o animal permanece lambendo a pata (índice de dor), ou diretamente na medula espinhal (dor/estímulo central), para avaliar quanto tempo o animal permanece lambendo a parte posterior do corpo (índice de dor). Em baixas doses também provoca alodínia e hiperalgesia.

Bradicinina: mediador endógeno e protéico da inflamação. Provoca dor, sensibilização e vasodilatação. Atua sobre receptores B2 (constitutivo) e B1 (indizível). Em altas doses, pode provocar dor espontânea, mas em doses mais baixas causa alodínia e hiperalgesia. Pode ser injetado na pata do animal, na medula espinhal ou em estruturas do cérebro.

Formalina: solução 2,5\% de formaldeído em solução salina (soro fisiológico). Inicialmente provoca a estimulação direta dos nervos periféricos (dor neurogênica, primeira fase) e, posteriormente, um processo inflamatório local (dor inflamatória, segunda fase). Normalmente é injetada na pata do animal, para avaliar o tempo em que o animal permanece lambendo a pata (índice de dor).

Ácido acético: solução 0,6-0,8\% que pode ser injetada no peritônio (cavidade abdominal) para induzir contorções abdominais (cólicas) através de um processo inflamatório local e passageiro, além da estimulação de receptores para ácido (asic) e mastócitos e macrófagos.

Histamina: mediador inflamatório endógeno derivado do aminoácido histidina. Normalmente é injetado na pata da cobaia, onde ativa receptores H1 que provocam dor espontânea em altas doses ou alodínia e hiperalgesia em baixas. Fisiologicamente está contida em grânulos no interior de mastócitos 
e em terminações nervosas. Também atua como neurotransmissor.

Glutamato: aminoácido excitatório (neurotransmissor), ativa os receptores glutamatérgicos (NMDA, AMPA/Kainato, mGlu). Igualmente é administrado na pata para avaliar o tempo que o animal permanece lambendo a pata injetada (dor periférica), ou na medula espinhal para avaliar o tempo de lambida da porção posterior do coro (dor/estímulo central).

Carragenina: polissacarídeo extraído de algas que provoca um processo inflamatório local temporário. Não provoca dor espontânea significativa, mas induz a formação de edema, alodínia e hiperalgesia.

Adjuvante completo de Freund (CFA): solução oleosa de Micobacterium tuberculosis inativado por calor. Induz um processo inflamatório local e crônico de difícil resolução. Com o tempo pode atingir nível sistêmico. Provoca a formação de edema, alodínia e hiperalgesia.

Cirurgia da pata: o animal é submetido à anestesia e a uma pequena incisão na parte plantar da pata, seguida por sutura. A simulação do processo cirúrgico induz a formação de alodínia mecânica na pata incisionada.

Imersão da pata/cauda: para avaliar a resposta do animal frente a um estímulo térmico é realizada a imersão da pata/cauda em um banho aquecido a $48^{\circ} \mathrm{C}$, para então cronometrar o tempo que o animal demora para retirar a pata/cauda da água.

Placa quente: o animal é posicionado sobre uma placa aquecida em temperatura ajustável, a fim de então cronometrar quanto tempo o animal demora para lamber as patas ou pular (Boyce-Rustay, Honore \& Jarvis, 2010)

\section{Etnografia das práticas laboratoriais}

Durante o período de acompanhamento do laboratório pudemos observar as seguintes práticas configuradas nos testes ali realizados:

1) O rotarod consiste em colocar o animal em um cilindro rotatório, fazendo-o caminhar por um período prolongado de tempo. É utilizado para determinar a capacidade locomotora em uma situação não espontânea (ou forçada). Isso se refere ao comprometimento do animal em realizar esforço muscular, causando consequentemente estresse, que é aferido quando o animal cai do aparelho. A partir desse teste é possível verificar a situação das cobaias que já estão sentindo alguma dor ou provocar nelas a dor para posterior tratamento.

2) No teste de Von Frey, os animais são colocados em pequenos espaços quadrados com uma tela embaixo. As cobaias ficam oclusas em pequenas caixas onde são vistas somente através de um vidro localizado em sua parte posterior para que o aplicador observe as reações dos animais testados. Os animais são colocados dentro dessas caixas com as substâncias que lhes causam dor. É realizada uma estimulação, normalmente na pata dos animais, com filamentos de espessura variada em diferentes momentos, e, dependendo de sua resposta, são transcritos um $\mathrm{X}$ ou um $\mathrm{O}$ em uma tabela, que constituem os dados usados para a tabulação. A finalidade do teste de Von Frey é medir ou estimular a dor nos animais ao tocar a área onde foi provocado o estímulo doloroso.

3) O teste de campo aberto (open field) é composto de uma caixa retangular de vidro, semelhante a um aquário, com 18 quadrados marcados na sua base (algo semelhante a um tabuleiro de xadrez) e serve para avaliar o nível de mobilidade da cobaia. Isto se dá ao aferir se o animal não responde ao estímulo doloroso por não estar sentindo dor, ou pelo fato de que sua pata está tão inchada que inviabiliza seu próprio deslocamento. Esse teste é feito de maneira que a locomoção ou a imobilidade do animal, dentro da caixa de vidro, seja registrada em uma tabela de transcrição de dados. As informações são coletadas todas as vezes que o animal passa de um quadrado para o outro e quando ele fica sobre as patas traseiras levantando as dianteiras. Para cada situação há uma gradação equivalente, de forma que o animal mais móvel e ágil alcança uma pontuação melhor. Indicando a capacidade exploratória de determinado animal ao investigar um novo ambiente apresentado, a partir deste teste é possível observar sua capacidade locomotora espontânea. Sua importância no contexto das práticas laboratoriais já especificadas dá conta de que comprometimentos nesses aspectos (locomoção) podem mascarar efeitos apresentados pelos tratamentos administrados.

Todos os testes são realizados após algum tempo de adaptação dos animais (normalmente 24 horas). Segundo uma pesquisadora, esse intervalo serve para que o animal se acostume ao ambiente e ao fato de ser manuseado constantemente. Destaca-se também a forma como esses animais são tratados nos entreatos dos testes quando se procura cercá-los de diversos cuidados como o ajuste da temperatura, da luminosidade, da umidade do ar, e oferecendo alimento e água de boa qualidade. Essas medidas fazem com que os animais tenham uma boa qualidade de vida, mesmo por curta duração. No decorrer de certos experimentos, até mesmo o tom de voz é controlado para que os animais tenham relativa tranquilidade no momento de sua utilização. Todo esse controle é feito em nome da melhor aplicação das técnicas de pesquisa, mas também presumindo assegurar o 
bem-estar dos animais. ${ }^{4}$ Essas estratégias de controle tanto do ambiente físico, naquilo que se aproxima da caracterização dos recintos como "ambientes de alta domesticação científica" (Marras, 2009), quanto das performances individuais protocoladas por uma espécie de "etiqueta" profissional parecem conformar animais em "estado natural" em modelos animais em "estado de natureza" adequados à representação das idiossincrasias humanas.

\section{Modelos não humanos}

$\mathrm{Na}$ tentativa de produzir e impingir essas dores nas cobaias, e assim de fato aproximá-las dos humanos, são feitas intervenções nos animais para criar condições próximas ao que é sentido pelos humanos. ${ }^{5}$ Como observado, todas essas categorias e modelos são criadas nos animais, que "naturalmente" não as possuem. Ao longo de nossa observação, em nenhum momento foram presenciados indícios de prazer (sádico) na produção das dores sentidas pelas cobaias. Inversamente, o que impera no discurso dos pesquisadores dá conta de que as cobaias devem ser utilizadas ao máximo antes de serem "descartadas". 6 No entanto, algumas vezes a cobaia não pode ser reutilizada, pois, ao término de uma experiência, encontra-se muito debilitada; ou ainda se nesta foi aplicada alguma substância capaz de interferir no resultado da experiência subsequente. Assim sendo, o animal deve ser induzido à morte. De forma intrigante, o pensamento vigente em laboratório parece orientar-se por um sistema de "duplo vínculo" (Bateson, 2000) ou através de uma dinâmica antitética (Sá, 2006) em que o respeito pela preservação da vida do animal prediz uma lógica utilitarista exacerbada, decorrendo do fato de que é na dor artificialmente construída que estes não humanos "naturalmente" devem se aproximar de nós.

\section{Dor e intersubjetividade}

A dor, dentro do laboratório, assume inúmeras facetas, estando presente em vários contextos, dentro ou fora das pesquisas, já que este não se resume a um espaço neutro de produção de ciência, mas sim em um local onde diversas trocas acontecem e são relacionadas à obtenção de conhecimento, às relações afetivas, às experiências de vida, bem como em qualquer outro ambiente de trabalho. Entretanto, esses aspectos invariavelmente são descartados ao longo do processo de purificação científica (Latour, 2001). A objetivação da dor, buscada nos referenciais chancelados pela ciência - leia-se, nos artigos científicos -, ignora outros processos correntes no ambiente de laboratório. O que poderia ser chamada de dimensão "metafísica" da dor, aqui nos remete, paradoxalmente, ao seu caráter fortemente empírico, afinal, dores e afecções são concretamente experienciadas ali - mais do que experimentadas - e compartilhadas entre seres humanos e não humanos. Em resumo, essa objetivação evidencia representações de dores humanas em sujeitos animais, tornando oclusas outras dores, igualmente reais, vivenciadas por sujeitos humanos.

Não surpreende, pois, a analogia traçada entre os traços subjetivos do laboratório e a subsistência das cobaias durante seu período de utilização. Ambos são responsáveis pela alimentação da corrente geradora de novas descobertas. E no final, ambos são necessariamente descartados, restando apenas uma Ciência (reificada em seus artigos) e um cadáver. ${ }^{7}$

A dor intersubjetiva presente no trabalho de campo dos cientistas é fruto de uma espécie de blues do pesquisador ao utilizar os animais, podendo se apresentar de diversas maneiras, mas sendo constante na relação sujeito-pesquisador e sujeito-objeto.

Embora seja necessário causar a dor nos animais ,não notamos nos pesquisadores uma explícita manifestação de pesar. Subentende-se que o ato de objetivar um não humano neste caso consista em artificialmente naturalizá-lo em algo de humano (suas dores). Isto nos leva a crer que seria ilógico sentir pena de um objeto que cumpre o papel de "bode expiatório" para os nossos sofreres. Vista dessa forma a morte das cobaias em oblação à humanidade aproxima-se da noção de sacrifício tal qual discorrida em Mauss \& Hubert (2005). Alheios à sua vontade, mas fiéis ao seu desígnio, os modelos animais cumprem representar os papéis sociais humanos numa relação de substituição de agências.

No entanto, subjetiva-se a relação com o objeto (cobaia) ao distanciá-lo do elemento que o humaniza.

4. Constituem exemplos desses "recintos" os biotérios e os laboratórios de pesquisa aplicada em biotecnologia, locais que permitem uma interação "controlada" dos processos de purificação de "formas orgânicas" ("modelos animais").

5. No caso trabalhado por Marras (2002), em que a utilização de cobaias busca evitar o chamado efeito placebo, a intenção justifica-se no recrutamento de "[...] doentes que mais se aproximam de ... ratos - isto é, aproximadamente análogos a seres que, supõe-se, sejam destituídos de reação subjetiva pronunciada. Esses, agora, os pacientes típicos"(p. 123).

6. Termo adotado no contexto laboratorial que indica a morte induzida de determinado animal.

7. Aproximando-nos ao que diz Michel Serres, em instigante documentário sobre as "lendas da ciência", analisando a poética/profética da obra de Julio Verne ("Da Terra à lua"), a descoberta/inovação científica já nasce acompanhada do elemento morte, tal como o cadáver do cão tornase satélite da espaçonave pensada pelo célebre escritor francês. 
Desse modo, ainda que possa soar paradoxal, é concebível pesar um não humano através da acentuação de sua alteridade que o faz "sujeito não humano", mas impensável apiedar-se dele em sua condição aproximativa que o torna um "objeto quase humano". Essa nova abordagem aproxima-se daquela sugerida por Haraway, em seu artigo "Sharing suffering" (2008), na qual mais importante do que a perspectiva antropomórfica sobre as cobaias de laboratório estaria a questão do "compartilhamento de sofrimento". Essa partilha só pode efetivamente se dar no momento em que as ditas cobaias sustentam sua própria condição não humana. A dor não pode ser, nesse caso, suportada simetricamente, ela é consequência de práticas historicamente situadas de distinção hierárquica que tornam uns "matáveis" e outros não (Haraway, 2008).

Essa lógica é ilustrada em situações-limite, como no transcorrer de determinado evento de dor aguda causada por morfina em um animal (classificada como uma dor terrível em que a cobaia corre e se contorce gritando), ouviam-se expressões vindas dos pesquisadores como "é tão legal". E, inversamente, quando é necessário terminar com a vida da cobaia (agora um sujeito não humano), pode-se perceber nesse corpus as mais diversas formas de expressão da dor humana. É o que dão conta relatos de pesquisadores: "Eu não gosto muito de matar, mas é preciso", bem como situações como a da pesquisadora que chorou compulsivamente enquanto matava um animal, ou a do pesquisador que demorou um longo tempo para conseguir descartar um animal, pois sentia medo do que estava fazendo. Existem ainda associações como a feita pela pesquisadora que dizia não poder matar os animais enquanto estava na TPM (tensão pré-menstrual), período em que, segundo ela, o sentimento maternal seria muito grande e a impediria de fazer o descarte.

As formas de "descarte" mais comuns utilizadas neste laboratório são o deslocamento de cabeça, feito com as próprias mãos do pesquisador, ou através de uma injeção letal. Outra alternativa, a decapitação, feita normalmente com uma tesoura, não foi observada por nós no decorrer da pesquisa. Inequivocamente, todos esses procedimentos terminam na incineração dos restos mortais das cobaias. Se considerarmos que essas técnicas revestem-se como verdadeiros rituais, previstos inclusive em manuais de orientação bioética, podemos notar que alguns pesquisadores têm reações adversas quando o momento do descarte dos animais se aproxima. Essas reações vão desde a recusa em efetuar o descarte, e neste caso, pede-se ajuda àqueles que dão menos importância ao ato, até a incontinência do choro. Ainda assim, a grande maioria dos envolvidos nas pesquisas consegue executar os animais quando necessário.

Há uma grande preocupação com o desperdício dos animais, que, antes de serem descartados, devem ser largamente utilizados. Trata-se de uma regra que justifica casos como o presenciado durante uma experiência de aplicação de determinado fármaco em camundongos, cuja finalidade era observar se a utilização daquela substância poderia gerar ulcerações no estômago dos animais. Iniciou-se observando o estômago de um animal sobre o qual não havia consenso se existia certa alteração estomacal. A partir daí foram utilizados vários camundongos para tentar certificar-se da existência das úlceras, mesmo ignorando que cada estômago observado despenderia um animal morto. Eventos como este indicam que o clima de excitação gerado em torno da iminência de uma descoberta é capaz de minimizar a lástima utilitarista refletida na perda de um modelo animal, dando lugar, por sua vez, a um entusiasmado "tecnicídio" tecnicista.

É através das relações estabelecidas nessas práticas que se balizam as formas como os pesquisadores lidam com seus sentimentos. Se é impensável matar as cobaias "por prazer", também é desejável que os cuidados com a morte sejam cumpridos dentro do protocolo de sua pesquisa. As dores implicadas nas perdas das cobaias são calculadas em função da probabilidade de êxito de determinada pesquisa. Consequentemente, a satisfação, o prazer e o orgulho por angariar/acumular credibilidade científica fornecem ao cientista o paliativo essencial para suas dores de laboratório. Logo, a amenização desse blues relacionado à morte dos animais acontece quando o objetivo final dos trabalhos é alcançado através da publicação de artigos em periódicos prestigiosos, na apresentação de trabalhos e na construção de monografias, dissertações e teses. Assim, quando os objetivos são obtidos, estes são aceitos na Academia mais como um artefato legítimo do que como práticas bizarras de campo.

\section{Tópicos para uma etnografia dos sintéticos}

Num momento em que a antropologia volta-se para a observação dos diversos mecanismos de circulação e troca de bens materiais e simbólicos, presentes nas sociedades ocidentais, chamamos aqui a atenção para a existência de uma ampla rede sociotécnica envolvendo atores e seus interesses, agentes e reagentes, curas e males. Esse circuito congrega pesquisas que pressupõem a construção social de doenças em laboratório para o beneficiamento de novos fármacos, um lócus habitado por cientistas, empresas e consumidores.

As relações que unem aqueles que produzem conhecimentos sobre os medicamentos e o consumidor 
são mediadas por aquilo que denominamos genericamente como indústria farmacêutica, tendo no consumo de seus produtos a materialização dessas relações. É possível dizer que uma das extremidades dessa rede situa-se, no caso brasileiro, dentro dos laboratórios de pesquisa experimental em nossas universidades.

Um laboratório é um espaço que transcende a visão estreita que o toma como um lócus de produção de conhecimento isolado das tendências da política (inter)nacional ou alheio aos fatores subjetivos e valores particulares intrínsecos a cada pessoa que por ali transita. Melhor dizendo, trata-se de um mundo onde mundos são construídos.

Ainda hoje, adentrar este mundo constitui um exercício de alteridade impactante e complicado em função da desconfiança dos cientistas "nativos", somada à dificuldade para compreender a linguagem ali falada e pelas constantes indagações a respeito do real motivo da pesquisa antropológica e sua validade. Nenhum desses desafios caracterizase por ser estruturalmente específico e imposto pela pesquisa em laboratório, pois são situações já presentes nas etnografias ditas clássicas. É provável que a principal especificidade ocorra nas relações de poder preestabelecidas na entrada em campo. Se durante um bom tempo a antropologia pensava como os "nativos são os outros", a posição dos naturalistas dava conta de que "os objetos são os outros". Os cuidados relacionados à "objetivação" promovida pelos antropólogos são equivalentes à apreensão dos naturalistas em não subjetivar seus objetos. E, considerando o laboratório como um mundo que constrói novos mundos, poder-se-ia argumentar também que este é o cenário da criação de um cosmos ordenado, genericamente chamado ciência. Não surpreende pensar que as relações aqui também restrinjam a construção das descobertas científicas de alhures, afinal a (onto)lógica moderna delimita que "cientistas somos nós" e "antropólogos são vocês".

A rede, por sua vez, transborda o perímetro laboratorial, ao não se centrar apenas nas suas conexões entre pesquisadores, financiadores e consumidores, mas também nas articulações entre humanos e não humanos. Em uma etnografia de um laboratório de farmacologia - como se pretende - é preciso consi- derar as relações estabelecidas entre os pesquisadores e os animais utilizados como cobaias para os experimentos (ratos e camundongos), as noções de aplicabilidade impositiva de sintomas reificados em agentes e a expectativa das reações esperadas pelos reagentes. Trabalhar com esses coletivos implica reconhecer a necessidade de pensar sobre temas relacionados à bioética, já que a utilização de organismos animais não humanos nas experimentações é uma realidade incômoda, mesmo obedecendo a uma série de cuidados rituais na lida com estes. Outro ponto a ser evocado nesse tipo de estudo trata da clássica relação entre natureza e cultura, que novamente é colocada em questão no sentido de não mais entendê-la como um par antagônico, mas sim como conjunções aproximativas. Em nosso caso, a natureza da doença é artificialmente introduzida em um organismo (não humano) que, por sua vez, "naturalmente" não a portaria. Feito isto, a anomalia deve ser imediatamente combatida através da aplicação de um paliativo medicinal construído artificialmente (nurture). Também artificialmente formam-se os modelos associativos entre humanos e não humanos na medida em que para nós, antropólogos da ciência, caberia perguntar o que seria mais relevante: buscar comparações entre seres humanos e cobaias que justifiquem introduzir sintomas de males de uns nos outros, ou admitir que a própria relação natureza-cultura é também sintetizada em laboratório? Nossa intuição nos direciona para a última opção.

Mesmo que este estudo nos inspire visualizar um mecanismo organizado em círculo, orientando suas ações, motivações e produtos de forma que se retroalimentem, é importante delimitar um ponto de referência para a pesquisa etnográfica. No exemplo tratado neste artigo, ao mesmo tempo em que aventamos diversas outras possibilidades de desdobramentos para esta pesquisa - como etnografar indústrias, práticas de consumo e aprofundarmo-nos nos hábitos e significados que os usuários experimentam ao associar-se aos fármacos -, é preciso destacar que toda incursão em um laboratório de pesquisa segrega uma gama de possibilidades para pensar antropologicamente os processos de criação de objetos, de transformação de substâncias e de metamorfose de sujeitos. 


\title{
Referências
}

ARANHA FILHO, Jayme. Legiões de objetos, atrás do tapume da ala dos fundos de um museu de ciências. In: ENCONTRO ANUAL DA ASSOCIAÇÃO BRASILEIRA DE PÓS-GRADUAÇÃO E PESQUISA EM CIÊNCIAS SOCIAIS, 2008.

BATESON, Gregory. Steps to an ecology of mind. Chicago and London: The University of Chicago Press, 2000.

BOYCE-RUSTAY, J. M.; HONORE, P.; JARVIS, M.F. Animal models of acute and chronic inflammatory and nociceptive pain. Methods in Molecular Biology, n. 617, p.4155, 2010.

HARAWAY, D. When species meet. Minneapolis: University of Minnesota Press, 2008.

LATOUR, B. A esperança de Pandora: ensaios sobre a realidade dos estudos científicos. Bauru: Edusc, 2001.

MARRAS, S. Recintos e evolução: capítulos de antropologia da ciência e da modernidade. 2009. Tese (Doutorado em Antropologia) - Universidade de São Paulo, São Paulo, 2009.

Ratos e homens e o efeito placebo: um reencontro da cultura no caminho da natureza. Campos: Revista de Antropologia Social, v. 2, p.117-33, 2002.

MAUSS, M.; HUBERT, H. Sobre o sacrifício. São Paulo: Cosac Naify, 2005.

SÁ, G. J. da S. No mesmo galho: ciência, natureza e cultura nas relações entre primatólogos e primatas. 2006. Tese (Doutorado em Antropologia) - Universidade Federal do Rio de Janeiro. Rio de Janeiro, 2006.

SAUTCHUK, C. E. Ciência e técnica. In: MARTINS, C. B.; DUARTE, L. F. D. (org.). Horizontes das Ciências Sociais no Brasil: Antropologia. São Paulo: Anpocs, 2010. p. 97-122.

\section{Experience and disposal: human and non-human pains in a laboratory of neurotoxicity and psychopharmacology}

\begin{abstract}
This work is based on ethnographic incursions carried out in a laboratory of neurotoxicity and psychopharmacology situated in a Brazilian university. From the description of the space and the practices of agents working there, we intend to give emphasis to some issues such as those relating to forms of classification and categorization of the even-concept pain as it is constructed and registered in the laboratory. We also inquire the use of non-human animal models (rats and mice) in projective experiments. Finally, we treat the mapping of sociotechnical network in which these actors and procedures are embedded.
\end{abstract}

Keywords: ethnography of laboratory; pain; animals; medicines; anthropology of science.

\section{Experiencia y descarte: suplicios humanos y no humanos en un laboratorio de neurotoxicología y psicofarmacología}

\section{Resumén}

Este trabajo se basea en las incursiones etnográficas llevadas a cabo en un laboratorio de neurotoxicidad y psicofarmacología situado en una universidad brasileña. A partir de una descripción en profundidad del espacio y las prácticas de los agentes que trabajan allí, buscamos, en este momento, dar énfasis a algunos hechos observados, como las relativas a las formas de clasificación y categorización del evento-concepto dolor que se inscribió en lo ambiente construido del laboratorio. Problematizamos también la utilización de modelos animales no humanos (ratas y ratones) como cobayas en experimentos de proyección. Por último, el tratamiento de la cartografía de las redes socio-técnicas en las que estos actores y los procedimientos están inmersos.

Palabras clave: etnografía de laboratorio; dolor; animales; fármacos; antropología de la ciencia. 